\title{
Gait Data for Efficient Gender Recognition
}

\author{
Zehra Karapinar Senturk ${ }^{1 *}$ \\ 1* Duzce University, Faculty of Engineering, Department of Computer Engineering, Duzce, Turkey, (ORCID: 0000-0003-3116-1985), zehrakarapinar@duzce.edu.tr
} (International Conference on Design, Research and Development- 20 - 22 October 2021)

(DOI: $10.31590 /$ ejosat.1040002)

ATIF/REFERENCE: Karapinar Senturk Z. (2021). Gait Data for Efficient Gender Recognition. European Journal of Science and Technology, (32), 27-31.

\begin{abstract}
Biometric recognition applications have been frequently used nowadays mostly because of reliability and ease of use for automated detection. There are many applications based on eyes, face, fingerprint, and voice for authentication and gender classification. In this paper, we focused on gender detection using the features of the steps of people. A different biometric sign has been investigated. Gait analyses were examined to determine the gender information of the people. Basic parameters like speed, variability, and symmetry of a gait, its several temporary, spatial, and height parameters, which were obtained via Physilog 5 sensor, were used in the analysis. A 321 $\mathrm{D}$ feature vector was comprised based on these features and an Artificial Neural Networks (ANN) model was trained with them. 95.83\% accuracy was obtained. The experimental results show the success of the proposed ANN-based gait analysis system against the stateof-the-art for gender classification.
\end{abstract}

Keywords: Artificial Neural Networks, Gait Analysis, Gender Classification

\section{Etkili Cinsiyet Tanıma için Yürüyüş Verisinin Kullanımı}

\section{$\ddot{O} z$}

Biyometrik tanıma uygulamaları, çoğunlukla otomatik algılama için güvenilirlik ve kullanım kolaylığı nedeniyle günümüzde sıklıkla kullanılmaktadır. Kimlik doğrulama ve cinsiyet sınıflandırması için göz, yüz, parmak izi ve sese dayalı birçok uygulama bulunmaktadır. $\mathrm{Bu}$ makalede, insanların adımlarının özelliklerini kullanarak cinsiyet tespiti üzerinde durduk. Farklı bir biyometrik işaret araştırıldı. Kişilerin cinsiyet bilgilerini belirlemek için yürüyüş analizleri yapıldı. Bir yürüyüşün hızı, değişkenliği, simetrisi gibi temel parametreleri, Physilog 5 sensörü ile elde edilen çeşitli geçici, uzamsal ve yükseklik parametreleri analizde kullanılmıştır. Bu öznitelikler temel alınarak bir 321-D öznitelik vektörü oluşturulmuş ve bunlarla bir Yapay Sinir Ağları (YSA) modeli eğitilmiştir. \%95.83 doğruluk elde edildi. Deneysel sonuçlar, önerilen YSA tabanlı yürüyüş analizi sisteminin cinsiyet sınıflandırması için en son teknolojiye karşı başarısını göstermektedir.

Anahtar Kelimeler: Yapay Sinir Ağları, Yürüyüş Analizi, Cinsiyet Sınıflandırması.

\footnotetext{
*Corresponding Author: zehrakarapinar@duzce.edu.tr
} 


\section{Introduction}

Gender is one of the significant characteristics of human beings. Gender recognition is important for some applications especially in the entertainment and commercial domains such as virtual reality-enhanced computer games, computer-aided physiological analysis, and e-commerce. Several biometric signs have been used for gender recognition until today. Face ((Rwigema et al., 2021), (Chandra Sekhar Reddy et al., 2020), (Swaminathan et al., 2020), (Chen et al., 2019), (Duan et al., 2018)), pupil size ((Cascone et al., 2020)), handwriting ((Gattal et al., 2018)), speech ((Qawaqneh et al., 2017), (Barkana \& Zhou, 2015), (Kaya et al., 2017)), nose shape ((Lv et al., 2019)), and social media recordings ((Reynaldo et al., 2019)) are the mediums used in gender recognition.

Gait analysis has been used in the literature for different purposes. Kitade et al. (Kitade et al., 2020) analyzed the gait of patients with cervical myelopathy. The severity classification has been performed using spatiotemporal, kinematic, and kinetic features obtained via a special motion analysis environment. Nuttaki et al. (Nutakki et al., 2020) used the kinematic data obtained from the sensors located to the several joints of the people to classify stance and swing. They analyzed the stance and swing features of female and male samples. It was suggested that the differences between male and female stance/swing features can be exploited in prosthesis design. Prabhu et al. (Prabhu et al., 2020) used a gait signal to classify neurodegenerative diseases since it is a good indicator of some malfunction in brain parts and nervous system. The gait parameters were extracted from gait signals of thirteen subjects through Recurrence Quantification Analysis. Amyotrophic Lateral Sclerosis, Huntington, and Parkinson's were classified via Support Vector Machines (SVM) and ANN. There are more papers on Parkinson's diagnosis via gait analysis ((Zeng et al., 2016), (Nishida et al., 2021), (Horin et al., 2021)).

Rather than those, gait analysis was also used in gender recognition studies. Isaac et al. (Isaac et al., 2019) used gait videos of people to recognize their gender information. They used a heavy preprocessing step to extract the gait features and a Bayesian classifier with a pose-based voting method to achieve $100 \%$ accuracy. Jain and Kanhangad (Jain \& Kanhangad, 2018) used a smartphone to obtain gait data for gender recognition. The features were extracted from gait cycles using a histogram of gradients. They achieved $88.21 \%$ accuracy on average using the bootstrap aggregating method for classification. Zakaria et al. (Zakaria et al., 2015) used a special motion system to retrieve kinematic data from the children to determine their gender. 83.33\% accuracy was achieved using an ANN-based application. Although, obtaining input data is quite expensive in this method. It requires an expensive set up with so many sensors and cameras. Therefore, it is not feasible. Instead of photo or video-based solutions, Pathan et al. (Pathan et al., 2020) used an inertial sensor-based gait dataset to determine the gender of the people in order not to violate the privacy of the people. Four machine learning algorithms were employed for the analysis including SVM, K-Nearest Neighbor (K-NN), Bagging, and Boosting. Bagging with the selection of 84 useful features over 104 was shown to be better among others with an accuracy of $87.85 \%$. Gumuscu et al. (Gumuscu et al., 2018) also used a simple sensorbased method for the purpose. The participants in the experiments were worn Physilog 5 sensor and made walked through a path.
The features collected during this walk were analyzed with SVM, $\mathrm{K}-\mathrm{NN}$, and decision tree methods. The decision tree was found to be the most effective method for gender recognition.

Although several researchers used gait data for gender recognition, their methods were either expensive or lack sufficient accuracy. In this paper, we used gait data provided by Gumuscu et al. (Gumuscu et al., 2018) to automatically determine the gender of the people. The walking patterns of the people were used for the gender classification, which is very rare and not sufficiently effective in the literature. ANN was employed for automated recognition. The proposed method will enable the development of many new gait-based solutions for different problems since it is a cheap, accurate, and easy method providing that the right to respect the privacy of the people is preserved during recognition.

This paper is organized as follows: Section 2 gives the details of the dataset and the method in detail, Section 3 presents the experimental results, and Section 4 concludes the paper with future works.

\section{Material and Method}

\subsection{Gait Dataset}

Abdulkadir Gumuscu donated the dataset for the gait analysis (Gümüşçü, 2019). The dataset is composed of 321 gait features of 16 people, 7 females and 9 males. Each person with a Physilog 5 sensor of Gait Up company (Physilog ${ }^{\circledR}$ | Inertial Measurement Sensor (IMU), n.d.) on their shoes was required to walk around a $5 \times 10$ walking track as shown in Fig. 1 and their gait data was recorded. Each sample in this dataset completed the path 3 times and therefore there are 3 rows in the dataset for 1 person. In total, there are 48 rows and 321 columns in the dataset, each row representing one round. Gait features obtained via the sensor are represented in Table 1 . These features may reveal different aspects, but in this paper, we focused on if gender can be accurately detected via gait data.

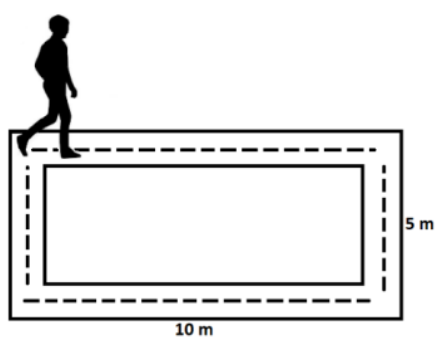

Figure 1. The walking track

\subsection{ANN for gait data-based gender classification}

ANN has been used in many different applications effectively for decades. The adaptivity, non-linearity, and fault-tolerance properties of the ANN make it preferred. ANN provides computational models which are inspired by the human brain. The parallel layers with a variable number of simple processing units, i.e. neurons, acquire, store, and process the data, and the weights of the connections determine the strength of the input signals. The knowledge is attained through a learning process made up of updating the network parameters such as the connection weights and the biases. Once the learning process stops, this means the network is matured enough, i.e. it has the generalization ability and can differentiate the classes of the samples. 
In this study, we generated a pattern recognition neural network using MATLAB 2019 software. It is a feedforward network that can classify inputs according to their target classes. There are several design parameters for this network and these parameters should be adjusted properly for an accurate model. The number of hidden layers, the number of neurons in hidden layers, and the backpropagation training function are the design parameters of the network. The biggest drawback of an ANNbased classification model is that there is no certain model that is capable of accurately classifying instances of some problems. The best model can only be determined by the trial and error method. Therefore, all possible alternatives, i.e. all parameter combinations, should be tried and the best parameter combination should be determined for the problem at hand. Table 2 shows the possible parameter values of the network. As seen from the table, the possible alternatives of the networks are infinity. Because a network may have 1 to infinity hidden layers and hidden neurons in theory. Since training infinitely many neural networks are impossible, in this study we investigated as many parameter combinations as possible. The parameter combination of the best model will be given in the Experimental Results section.

\section{Results}

Before going into the experiments, the dataset was first divided randomly into two sets, namely training and test sets. The training set consists of $70 \%$ of the samples and the test set consists of $30 \%$ of them. Samples of the test set were never used during training the network for an objective performance evaluation. The network naturally produces proper outputs for the samples in the training set since it updates its weights to produce correct outputs to the training samples. Proper testing is possible with previously unknown samples and this is a measurement of how the network generalizes.

Table 1. Gaint Features (Gumuscu et al., 2018)

\begin{tabular}{|l|l|l|}
\hline No & $\begin{array}{l}\text { Feature } \\
\text { Class }\end{array}$ & Features \\
\hline 1 & $\begin{array}{l}\text { Basic } \\
\text { Parameters }\end{array}$ & Speed, Variability, Symmetry \\
\hline 2 & $\begin{array}{l}\text { Temporary } \\
\text { Parameters }\end{array}$ & $\begin{array}{l}\text { Heel Press Time, Cycle Time, Cadence, } \\
\text { Posture, Oscillation, Loading, Foot } \\
\text { Press, Thrust, Double Support }\end{array}$ \\
\hline 3 & $\begin{array}{l}\text { Spatial } \\
\text { Parameters }\end{array}$ & $\begin{array}{l}\text { Step Length, Step Speed, Peak Angle } \\
\text { Speed, Maximum Swing Speed, } \\
\text { Rotation Angle, Step Angle, Lift Angle, } \\
\text { Swing Width, 3D Path Length }\end{array}$ \\
\hline 4 & $\begin{array}{l}\text { Height } \\
\text { Parameters }\end{array}$ & $\begin{array}{l}\text { Maximum Heel Height, Maximum } \\
\text { Finger Tip Height, Minimum Finger } \\
\text { Tip Height }\end{array}$ \\
\hline
\end{tabular}

Table 2. Networks Parameters

\begin{tabular}{|l|l|l|}
\hline No & Parameter & Possible values \\
\hline 1 & $\begin{array}{l}\text { Number of hidden } \\
\text { layers }\end{array}$ & 1 to $\infty$ \\
\hline 2 & $\begin{array}{l}\text { Number of neurons } \\
\text { in hidden layers }\end{array}$ & 1 to $\infty$ \\
\hline 3 & $\begin{array}{l}\text { Backpropagation } \\
\text { training function }\end{array}$ & $\begin{array}{l}\text { Levenberg-Marquardt, Bayesian } \\
\text { Regularization, Scaled } \\
\text { Conjugate Gradient, Gradient } \\
\text { Descent (with Momentum), } \\
\text { Variable Learning Rate Gradient } \\
\text { Descent, etc. }\end{array}$ \\
\hline
\end{tabular}

The optimum parameters that provide the best classification accuracy are given in Table III. These parameters were decided after a series of experiments. Fig. 2 shows the confusion matrices of the training/test processes and their combination. Zeros in the confusion matrices stand for the male samples and the ones represent the female samples. Although there is no misclassification for the training samples as expected, there is only one misclassification for the test samples. Among 10 test samples (5 males and 5 females), one female sample was classified as male and no male sample was misclassified.

Based on the confusion matrix, several performance metrics can be calculated. The most prevalent metrics for the evaluation and the comparison of the classification methods are accuracy, sensitivity, specificity, and precision. Therefore, the performance of the proposed method was also measured using these metrics. Equations (1) - (4) show how to calculate the metrics respectively.

$$
\begin{gathered}
\text { Accuracy }=\frac{T P+T N}{T P+T N+F P+F N} \\
\text { Sensitivity }=\frac{T P}{T P+F N} \\
\text { Specificity }=\frac{T N}{T N+F P} \\
\text { Precision }=\frac{T P}{T P+F P}
\end{gathered}
$$

The abbreviations in (1) - (4) mean TP: Number of females classified as female, TN: Number of males classified as male, FP: Number of males classified as female, FN: Number of females classified as male.

Table 3. Parameters of the Best Network

\begin{tabular}{|l|l|l|}
\hline No & Parameter & Value \\
\hline 1 & Number of hidden layers & 1 \\
\hline 2 & Number of neurons in hidden layers & 5 \\
\hline 3 & Backpropagation training function & $\begin{array}{l}\text { Levenberg - } \\
\text { Marquardt }\end{array}$ \\
\hline
\end{tabular}

Table 4. Performance Metrics of Gait Data-Based Gender Classification Method

\begin{tabular}{|c|c|c|c|}
\hline Accuracy & Sensitivity & Specificity & Precision \\
\hline $90.00 \%$ & $80.00 \%$ & $100 \%$ & $100 \%$ \\
\hline
\end{tabular}

Table IV shows the test performance of the proposed gait data-based gender classification method based on the aforementioned metrics. It should be noted that these metrics were obtained for the test confusion matrix. When the combination of the training and test confusion matrices are considered, these metrics will take better values. For example, although the accuracy for test samples is $90 \%$, it is $97.87 \%$ when all the samples are considered. We respect the test metrics to show the performance of the network because the classification ability for the unseen samples is important. 
Table 5. Comparison with the State-of-the-Art

\begin{tabular}{|l|l|l|l|}
\hline Ref. No & Method & Accuracy & Number of Features \\
\hline $\begin{array}{l}\text { (Gumuscu } \\
\text { et al., } \\
\text { 2018) }\end{array}$ & K-NN & $84.00 \%$ & 321 \\
\hline $\begin{array}{l}\text { (Pathan et } \\
\text { al., 2020) }\end{array}$ & Bagging & $87.85 \%$ & 84 \\
\hline Proposed & ANN & $\mathbf{9 0 . 0 0 \%}$ & $\mathbf{3 2 1}$ \\
\hline
\end{tabular}
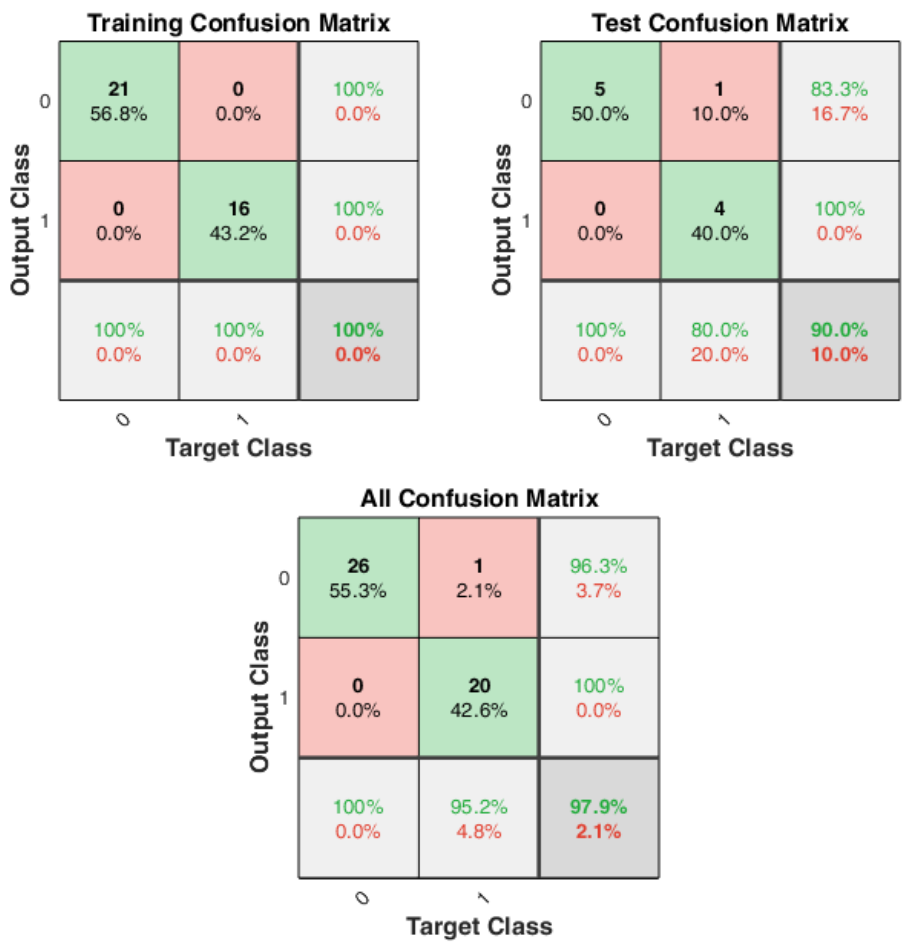

Figure 2. Training and test confusion matrices

To show the success of the proposed method, we also compared it with the state-of-the-art gait data-based gender recognition studies. Table $\mathrm{V}$ shows the comparison results. The proposed method is well ahead of the state-of-the-art in terms of accuracy. Although (Pathan et al., 2020) used a fewer number of features for the detection, their accuracy is lower.

For the evaluation of the method, we also took the computation time into account. Training and testing of the proposed ANN-based gender classification method took 2.177 seconds. The trained model can determine the class of an unseen sample in less than 0.02 seconds on average. These results show that the proposed method accurately decides about gender in a very short time, which enables it to be used in real-time applications.

\section{Conclusion}

Biometric signs have been frequently used in many applications for their reliability and ease of use. In this paper, a rare biometric sign has been used for gender classification. Gait data of the people were used to determine the gender of the participants. The proposed ANN-based method can almost accurately differentiate the male samples from the females. All the males were recognized perfectly. We showed that gait data carries serious clues related to gender. This study showed that ANN is more successful than the other state-of-the-art methods for gender detection. The proposed method can be effectively used in gender- specific personal applications such as virtual reality apps or ecommerce. Besides, it is also important to make the analysis providing that the right to respect the privacy of the people is preserved. Thanks to a simple sensor device worn on a shoe, the privacy concern vanishes, and people are not obliged to give photos or video for the analyses.

In future studies, we will focus on feature elimination methods for gait data-based gender recognition. Also, different biometrics and larger datasets will be investigated.

\section{Acknowledge}

I would like to thank Dr. Abdulkadir Gumuscu for his kind and encouraging help in understanding the dataset and using it for gender detection.

\section{References}

Barkana, B. D., \& Zhou, J. (2015). A new pitch-range based feature set for a speaker's age and gender classification. Applied Acoustics, 98, 52-61. https://doi.org/10.1016/j.apacoust.2015.04.013

Cascone, L., Medaglia, C., Nappi, M., \& Narducci, F. (2020). Pupil size as a soft biometrics for age and gender classification. Pattern Recognition Letters, 140, 238-244. https://doi.org/10.1016/j.patrec.2020.10.009

Chandra Sekhar Reddy, P., Sarma, K. S. R. K., Sharma, A., Varaprasada Rao, P., Govinda Rao, S., Sakthidharan, G. R., \& Kavitha, K. (2020). Enhanced age prediction and gender classification (EAP-GC) framework using regression and SVM techniques. Materials Today: Proceedings. https://doi.org/10.1016/j.matpr.2020.10.857

Chen, Z., Edwards, A., Gao, Y., \& Zhang, K. (2019). Learning discriminative subregions and pattern orders for facial gender classification. Image and Vision Computing, 89, 144-157. https://doi.org/10.1016/j.imavis.2019.06.012

Duan, M., Li, K., Yang, C., \& Li, K. (2018). A hybrid deep learning CNN-ELM for age and gender classification. Neurocomputing, 275, 448-461. https://doi.org/10.1016/j.neucom.2017.08.062

Gattal, A., Djeddi, C., Siddiqi, I., \& Chibani, Y. (2018). Gender classification from offline multi-script handwriting images using oriented Basic Image Features (oBIFs). Expert Systems with Applications, 99, 155-167. https://doi.org/10.1016/j.eswa.2018.01.038

Gümüşçü, A. (2019). Giyilebilir Yürüyüş Analiz Sensörü ile Kişi Sınıflandırmasının Öznitelik Seçme Algoritmaları ile İyileştirilmesi. In Fırat Üniversitesi Müh. Bil. Dergisi (Vol. 31, Issue 2).

Gumuscu, A., Karadag, K., Caliskan, M., Tenekeci, M. E., \& Akaslan, D. (2018). Gender classification via wearable gait analysis sensor. 26th IEEE Signal Processing and Communications Applications Conference, SIU 2018, 1-4. https://doi.org/10.1109/SIU.2018.8404181

Horin, A. P., Myers, P. S., Pickett, K. A., Earhart, G. M., \& Campbell, M. C. (2021). Resting-state functional connectivity associated with gait characteristics in people with Parkinson's disease. Behavioural Brain Research, 113398. https://doi.org/10.1016/j.bbr.2021.113398 
Isaac, E. R. H. P., Elias, S., Rajagopalan, S., \& Easwarakumar, K. S. (2019). Multiview gait-based gender classification through pose-based voting. Pattern Recognition Letters, 126, 41-50. https://doi.org/10.1016/j.patrec.2018.04.020

Jain, A., \& Kanhangad, V. (2018). Gender classification in smartphones using gait information. Expert Systems with Applications, 93, 257-266. https://doi.org/10.1016/j.eswa.2017.10.017

Kaya, H., Salah, A. A., Karpov, A., Frolova, O., Grigorev, A., \& Lyakso, E. (2017). Emotion, age, and gender classification in children's speech by humans and machines. Computer Speech and Language, 46, 268-283. https://doi.org/10.1016/j.csl.2017.06.002

Kitade, I., Nakajima, H., Takahashi, A., Matsumura, M., Shimada, S., Kokubo, Y., \& Matsumine, A. (2020). Kinematic, kinetic, and musculoskeletal modeling analysis of gait in patients with cervical myelopathy using a severity classification. Spine Journal, 20(7), 1096-1105. https://doi.org/10.1016/j.spinee.2020.01.014

Lv, C., Wu, Z., Zhang, D., Wang, X., \& Zhou, M. (2019). 3D Nose shape net for human gender and ethnicity classification. Pattern Recognition Letters, 126, 51-57. https://doi.org/10.1016/j.patrec.2018.11.010

Nishida, D., Mizuno, K., Yamada, E., Tsuji, T., Hanakawa, T., \& Liu, M. (2021). Correlation between the brain activity with gait imagery and gait performance in adults with Parkinson's disease: A data set. Data in Brief, 36, 106993. https://doi.org/10.1016/j.dib.2021.106993

Nutakki, C., Mathew, R. J., Suresh, A., Vijay, A. R., Krishna, S., Babu, A. S., \& Diwakar, S. (2020). Classification and Kinetic Analysis of Healthy Gait using Multiple Accelerometer Sensors. Procedia Computer Science, 171, 395-402. https://doi.org/10.1016/j.procs.2020.04.041

Pathan, R. K., Uddin, M. A., Nahar, N., Ara, F., Hossain, M. S., \& Andersson, K. (2020). Gender Classification from Inertial Sensor-Based Gait Dataset. International Conference on Intelligent Computing and Optimization, 583-596. https://doi.org/10.1007/978-3-030-68154-8_51

Physilog ${ }^{\circledR}$ | Inertial Measurement Sensor (IMU). (n.d.). Retrieved June 3, 2021, from https://research.gaitup.com/physilog/

Prabhu, P., Karunakar, A. K., Anitha, H., \& Pradhan, N. (2020). Classification of gait signals into different neurodegenerative diseases using statistical analysis and recurrence quantification analysis. Pattern Recognition Letters, 139, 10-16. https://doi.org/10.1016/j.patrec.2018.05.006

Qawaqneh, Z., Mallouh, A. A., \& Barkana, B. D. (2017). Age and gender classification from speech and face images by jointly fine-tuned deep neural networks. Expert Systems with Applications, 85, 76-86. https://doi.org/10.1016/j.eswa.2017.05.037

Reynaldo, N., Goenawan, Chanrico, W., Suhartono, D., \& Purnomo, F. (2019). Gender demography classification on instagram based on user's comments section. Procedia Computer Science, 157, 64-71. https://doi.org/10.1016/j.procs.2019.08.142
Rwigema, J., Mfitumukiza, J., \& Tae-Yong, K. (2021). A hybrid approach of neural networks for age and gender classification through decision fusion. In Biomedical Signal Processing and Control (Vol. 66, p. 102459). Elsevier Ltd. https://doi.org/10.1016/j.bspc.2021.102459

Swaminathan, A., Chaba, M., Sharma, D. K., \& Chaba, Y. (2020). Gender Classification using Facial Embeddings: A Novel Approach. Procedia Computer Science, 167, 26342642. https://doi.org/10.1016/j.procs.2020.03.342

Zakaria, N. K., Jailani, R., \& Tahir, N. M. (2015). Application of ANN in Gait Features of Children for Gender Classification. Procedia Computer Science, 76, 235-242. https://doi.org/10.1016/j.procs.2015.12.348

Zeng, W., Liu, F., Wang, Q., Wang, Y., Ma, L., \& Zhang, Y. (2016). Parkinson's disease classification using gait analysis via deterministic learning. Neuroscience Letters, 633, 268-278. https://doi.org/10.1016/j.neulet.2016.09.043 